\title{
Clonal variation in cone and seed production in black and white spruce seed orchards and management implications
}

\author{
by Gregory W. Adams ${ }^{1}$ and Hartmut A. Kunze ${ }^{1}$
}

Variation in cone and seed production across a range of clones in black and white spruce seed orchards was investigated in 1994. The purpose was to develop production information to be used with knowledge of orchard management practices to capture genetic gain more efficiently and improve clonal balance in orchard seedlots. Bulk cone collections were made from ten randomly selected trees for each of 48 clones and 60 clones of white spruce and black spruce, respectively. The average number of cones tree $^{-1}$ was determined for each clone. Seeds were extracted and average seeds tree ${ }^{-1}$, seeds cone $\mathrm{e}^{-1}$ and seeds $\mathrm{g}^{-1}$ were determined for each clone. Clones were ranked by cone and seed production and significant variation existed between the two ranks. For white spruce, a strong positive correlation was found between number of cones tree ${ }^{-1}$ and number of seeds, but the same was not found for black spruce, largely because some of the heaviest cone bearing clones produced lower amounts of sound seed. For both species, clones which produced more cones tree ${ }^{-1}$ tended to produce fewer seeds per cone and the seed was smaller than clones with more moderate levels of cone production. Clonal balance in cone and seed production is discussed with respect to practical orchard management options.

Key words: clonal variation, cone and seed production, seed orchard, black spruce, white spruce
La variation dans la production de cônes et de graines parmi une sélection de clones d'épinette noire et blanche croissant dans un verger à graines a été étudiée en 1994. L'objectif visé consistait à recueillir de l'information sur la production dans le but de l'utiliser conjointement avec les connaissances sur les pratiques d'aménagement des vergers pour accroître le gain génétique le plus efficacement possible et pour améliorer l'équilibre clonal au sein des graines issues du verger. La cueillette en vrac des cônes a été effectuée sur dix arbres choisis au hasard pour chacun des 48 clones d'épinette blanche et des 60 clones d'épinette noire. Le nombre moyen de cône par arbre a été déterminé pour chaque clone. Les graines ont été extraites et le nombre moyen de graines par arbre, de graines par cône, de graines par gramme, a été déterminé pour chaque clone. Les clones ont été classés selon la production de cônes et de graines. Une différence significative a été entifièe entre les deux niveaux. Dans le cas de l'épinette blanche, une forte corrélation a été relevée entre le nombre de cônes par arbre et le nombre de graines, mais la même corrélation n'a pas été retrouvée pour l'épinette noire, en grande partie parce que certains des clones produisant les cônes les plus lourds, contenaient les plus faibles quantités de graines complètes. Dans le cas des espèces, les clones qui ont produit plus de cônes par arbre avaient tendance à produire le moins de graines par cônes, graines qui étaient plus petites que les clones d'un niveau moyen de production de cônes. L'équilibre clonal entre la production de cônes et de graines est discuté en fonction des possibilités réalistes d'aménagement des vergers.

Mots clés: variation clonale, production de cônes et de graines, vergers à graines, épinette noire, épinette blanche

\section{Introduction}

Lack of balance in reproductive output among clones is prevalent in seed orchards (Zobel and Talbert 1984) and is one factor which contributes to non-panmictic mating. Large deviations from panmictic mating will result in a difference between realized gain from the seed orchard compared to predicted gain, as well as a potentially significant reduction in genetic diversity. The lack of balance may be related to variation in female cone and seed production among clones, pollen production and viability, phenology or any combination of these factors. Frequency-dependent male reproductive success has also been demonstrated for Douglas-fir (Pseudotsuga menziesii (Mirb.) Franco) (El-Kassaby and Ritland 1992).

A study was conducted in 1994 to examine the variation in cone and seed production across the range of white and black spruce clones represented at the J.D. Irving, Limited Parkindale Seed Orchard, located in Southeastern New Brunswick. This site includes first generation grafted clonal orchards of black spruce (Picea mariana (Mill.) B.S.P.), white spruce (Picea glauca (Moench) Voss), Norway spruce (Picea abies (L.) Karst), jack pine (Pinus banksiana Lamb.) and eastern larch

1J.D. Irving, Limited, Sussex Tree Nursery, R.R.\#4, Sussex, New Brunswick, Canada EOE 1P0.

(Larix laricina (Du Roi) K. Koch) as well as second generation orchards of black spruce and jack pine. Seed orchards were established between 1983 and 1991. Significant seed production began in 1988 and since 1992, all seed used in nursery production of these species, with the exception of Norway spruce, has originated from seed orchards.

When first generation orchards were established in Eastern Canada, there was insufficient knowledge regarding the levels of cone and seed production which could be expected from seed orchards (McPherson et al. 1982). In addition there was little experience with flower induction. As a result, a number of agencies have an excess of improved seed. Ample seed supply presents an opportunity for greater latitude in management to manipulate the composition of orchard seedlots through, for instance, more intensive genetic roguing or selective harvesting. This study was initiated to assess the cone and seed production of a wide range of clones in the seed orchards and provide operational information. The goal is to use this information as well as genetic test data to improve the genetic quality of orchard seed and the balance in clonal composition in orchard seedlots.

\section{Methods}

Ten trees were selected randomly, independantly of cone crop, from each clone in sections of the white and black spruce seed orchards established between 1985 and 1987. In these sections 
there were 60 and 48 clones of black spruce and of white spruce, respectively. No flower induction treatments had been applied for several years in the orchards and all trees were windpollinated (ie. no supplemental mass pollination). Prior to operational cone harvesting in August for white spruce and September for black spruce, all cones were picked from each of the ten trees per clone and they were bulked by clone. Total litres were measured, cone $\mathrm{L}^{-1}$ counts were made and cones tree $^{-1}$ was determined for all clones. The cones were held in open trays in a cone shed until processing began in November.

Processing by clonal parent was done between November and December, 1994. Lot sizes varied considerably, for instance, the range in black spruce was from $30 \mathrm{~L}$ to less than a litre. This necessitated the use of different extraction methods according to lot size. Those lots greater than approximately $5 \mathrm{~L}$ in volume were processed using a BCC (Björkemar Construction \& Consulting $\mathrm{AB}$ ) cone drying box kiln to open the cones, a $\mathrm{BCC}$ combination cone tumbler/dewinger to extract the seeds and remove the wings, and a $\mathrm{BCC}$ gravity separator to remove empty seeds. Approximately $60 \%$ of the white spruce lots and less than $10 \%$ of the black spruce lots were processed in this manner. Smaller lots were processed using a small scale homemade box cone dryer and cone tumbler. Dewinging was done by rubbing the seed in a cloth bag and removing the wings in a gravity separator. Total weight of sound seed and seeds $\mathrm{g}^{-1}$ were recorded for each clonal parent. The total sound seeds and total cones clone ${ }^{-1}$ were used to determine seeds cone ${ }^{-1}$ and total seeds tree ${ }^{-1}$ was also determined by clone. Height was measured for each of the trees and the average height for each clone was calculated and related to the cone and seed data.

\section{Results}

Clonal averages and ranges for tree height and cone and seed parameters are presented (Table 1). Average tree height was $265 \mathrm{~cm}$ for black spruce with a clonal range of 172 to $388 \mathrm{~cm}$. The white spruce averaged $367 \mathrm{~cm}$ in height with a range of 263 to $446 \mathrm{~cm}$. The range in clonal averages is explained by variation in the average age from grafting by clone and genetic differences in growth rates. As expected, there was large variation in cone and seed production among clones. For example the average sound seeds tree ${ }^{-1}$ ranged from 1 to 2819 for black spruce and 121-40950 for white spruce. While this study was not designed to estimate heritability of cone and seed production, these traits have been shown to be under strong genetic control in other conifers (El-Kassaby 1992). White spruce produced more than twice as many cones tree $\mathrm{e}^{-1}$ as black spruce ( 250 versus 104$)$ and over seven times as many seeds tree $^{-1}$ (6365 versus 797). The overall clonal average height was approximately 1 metre greater for white spruce than black spruce and this would result in a significantly larger crown area. In addition, white spruce cones are more widely distributed throughout the crown compared to black spruce where most of the cones are densely clustered in the upper $25 \%$ of the crown. The white spruce clones produced on average almost twice as many seeds cone $e^{-1}$ as black spruce (33 versus 18). Partial serotiny of black spruce cones may have influencd these results in that some viable seeds may not be extracted from the cones. Extraction was conducted according to operational protocols so the results reflect what happens in bulk processed cone collections. These represent results from a good year for conifer cone production (Simpson 1995), especially white spruce.
Table 1. Average tree height, cones tree ${ }^{-1}$, sound seeds tree ${ }^{-1}$, seeds cone ${ }^{-1}$, and seeds $\mathrm{g}^{-1}$ for black spruce and white spruce with clonal ranges in parenthesis

\begin{tabular}{llc}
\hline Criteria & Black spruce & White spruce \\
\hline Height $(\mathrm{cm})$ & $265(172-388)$ & $367(263-446)$ \\
Cones tree $^{-1}$ & $104(1-552)$ & $250(2-1006)$ \\
Seeds tree $^{-1}$ & $797(1-2819)$ & $6365(121-40950)$ \\
Seeds cone $^{-1}$ & $18(0-68)$ & $33(4-74)$ \\
Seeds g $^{-1}$ & $625(387-896)$ & $377(283-506)$ \\
\hline
\end{tabular}

Table 2. Pearson correlation matrix of white spruce height, cone and seed parameters with significance levels in parenthesis

\begin{tabular}{|c|c|c|c|c|}
\hline & Cones tree $^{-1}$ & Seeds tree ${ }^{-1}$ & Seeds cone ${ }^{-1}$ & Seeds $\mathrm{g}^{-1}$ \\
\hline Height $(\mathrm{cm})$ & $\begin{array}{c}-0.058 \\
(0.697)\end{array}$ & $\begin{array}{c}-0.011 \\
(0.942)\end{array}$ & $\begin{array}{c}\mathbf{0 . 1 5 7} \\
(0.286)\end{array}$ & $\begin{array}{c}-0.198 \\
(0.178)\end{array}$ \\
\hline Cones tree ${ }^{-1}$ & & $\begin{array}{c}\mathbf{0 . 6 9 7} \\
(0.000)\end{array}$ & $\begin{array}{c}-0.412 \\
(0.004)\end{array}$ & $\begin{array}{c}0.421 \\
(0.003)\end{array}$ \\
\hline Seeds tree ${ }^{-1}$ & & & $\begin{array}{c}\mathbf{0 . 0 9 3} \\
(0.528)\end{array}$ & $\begin{array}{c}\mathbf{0 . 1 7 6} \\
(0.232)\end{array}$ \\
\hline Seeds cone $e^{-1}$ & & & & $\begin{array}{c}-0.309 \\
(0.033)\end{array}$ \\
\hline
\end{tabular}

Table 3. Pearson correlation matrix of black spruce height, cone and seed parameters with significance levels in parenthesis

\begin{tabular}{|c|c|c|c|c|}
\hline & Cones tree $^{-1}$ & Seeds tree ${ }^{-1}$ & Seeds cone $e^{-1}$ & Seeds $\mathrm{g}^{-1}$ \\
\hline Height $(\mathrm{cm})$ & $\begin{array}{l}\mathbf{0 . 3 1} \\
(0.016)\end{array}$ & $\begin{array}{c}\mathbf{0 . 1 7 5} \\
(0.181)\end{array}$ & $\begin{array}{c}-0.314 \\
(0.015)\end{array}$ & $\begin{array}{c}-0.041 \\
(0.756)\end{array}$ \\
\hline Cones tree ${ }^{-1}$ & & $\begin{array}{c}0.204 \\
(0.117)\end{array}$ & $\begin{array}{c}-0.586 \\
(0.000)\end{array}$ & $\begin{array}{c}0.269 \\
(0.039)\end{array}$ \\
\hline Seeds tree ${ }^{-1}$ & & & $\begin{array}{c}\mathbf{0 . 0 8 9} \\
(0.499)\end{array}$ & $\begin{array}{c}-0.194 \\
(0.141)\end{array}$ \\
\hline Seeds cone $e^{-1}$ & & & & $\begin{array}{c}-0.531 \\
(0.000)\end{array}$ \\
\hline
\end{tabular}

Pearson product-moment correlation coefficients and significance levels among tree height and cone and seed parameters were determined for both species based on the clonal averages (Tables 2 and 3). For white spruce there was no significant correlation between clone height and cones tree ${ }^{-1}$, seeds tree ${ }^{-1}$, seeds cone $^{-1}$ or seeds $\mathrm{g}^{-1}$. In black spruce, there was a weak $(0.310)$ but significant correlation between height and cones tree ${ }^{-1}$. There was also a positive $(0.175)$ but not significant correlation between height and seeds tree ${ }^{-1}$. Cones tree ${ }^{-1}$ was strongly correlated with seeds tree ${ }^{-1}$ in white spruce $(0.697)$, but the relationship was weak (0.204) and not significant in black spruce. The reason for this is illustrated (Figs. 1 and 2). The 20 best seedproducing clones for each species were graphed showing the contribution of each clone to the overall per tree total for both cone and seed production tree ${ }^{-1}$. For white spruce, the sizes of the percentage contribution bars for cones and seeds are much more similar across the clones compared to black spruce. For black spruce, some clones produced large cone crops but unexpectedly small amounts of seeds (Fig. 2). For both white and black spruce, the number of cones tree ${ }^{-1}$ was significant and negatively correlated with seeds cone $\mathrm{e}^{-1}(-0.412$ and -0.586 ); trees with more cones tended to have fewer seeds cone ${ }^{-1}$. Similarly, for both species there were significant positive correlations between cones ramet ${ }^{-1}$ and seeds $\mathrm{g}^{-1}$ (trees with more cones produce smaller seed). The only other significant correlations were between seeds cone $\mathrm{e}^{-1}$ and seeds $\mathrm{g}^{-1}$ for both white and black spruce ( -0.309 and -0.531 , respectively). 

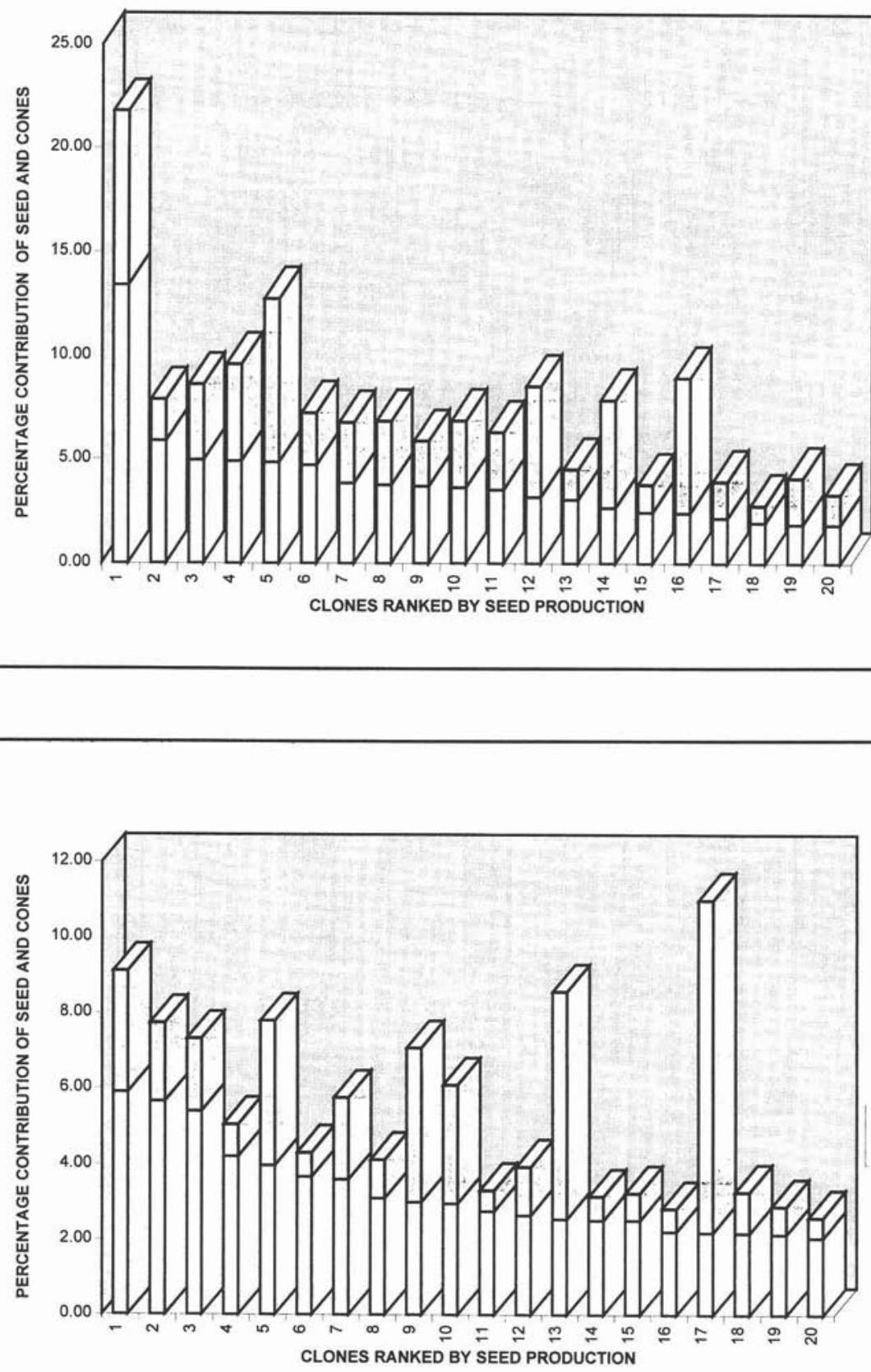

口Cones Per Tree 口Seeds Per Tree
Fig. 1. Ranked top 20 white spruce seed producing clones compared to recent percent contribution of total cone production.
Fig. 2. Ranked top 20 black spruce seed producing clones compared to recent percent contribution of total cone production.
These correlations indicate that cones with more sound seeds generally produced larger seed as well.

To examine the deviation from balanced cone and seed production, the clonal averages of cones tree ${ }^{-1}$ and seeds tree $^{-1}$ were expressed as percentages of totals across clones for both species. Clonal percentages were ranked by both cones tree $^{-1}$ and seeds tree ${ }^{-1}$ and cumulatively plotted against the percent of clones represented. The resulting graphs (Figs. 3 and 4) illustrate the deviation from perfectly balanced cone and seed production in a similar manner to El-Kassaby and Cook (1994). The curves presented for both species follow a roughly logarithmic shape. A small percentage of clones bore dis- proportionately large percentages of the total number of cones and seeds which resulted in a steep slope at the beginning of the curve. At the tail of the curve, there were a number of clones which produced low percentages of cones and seed and which resulted in a gentle slope. The straight lines on both graphs represent a situation of perfect reproductive balance. The cone and seed curves are plotted according to individual clone ranking for each trait and although the curves were similar in shape, the clonal ranking was very different between cone and seed contribution curves (Figs. 1 and 2). For white spruce, the cumulative percent curves for both cones and seed were nearly identical. The black spruce curves showed that the cumulative 

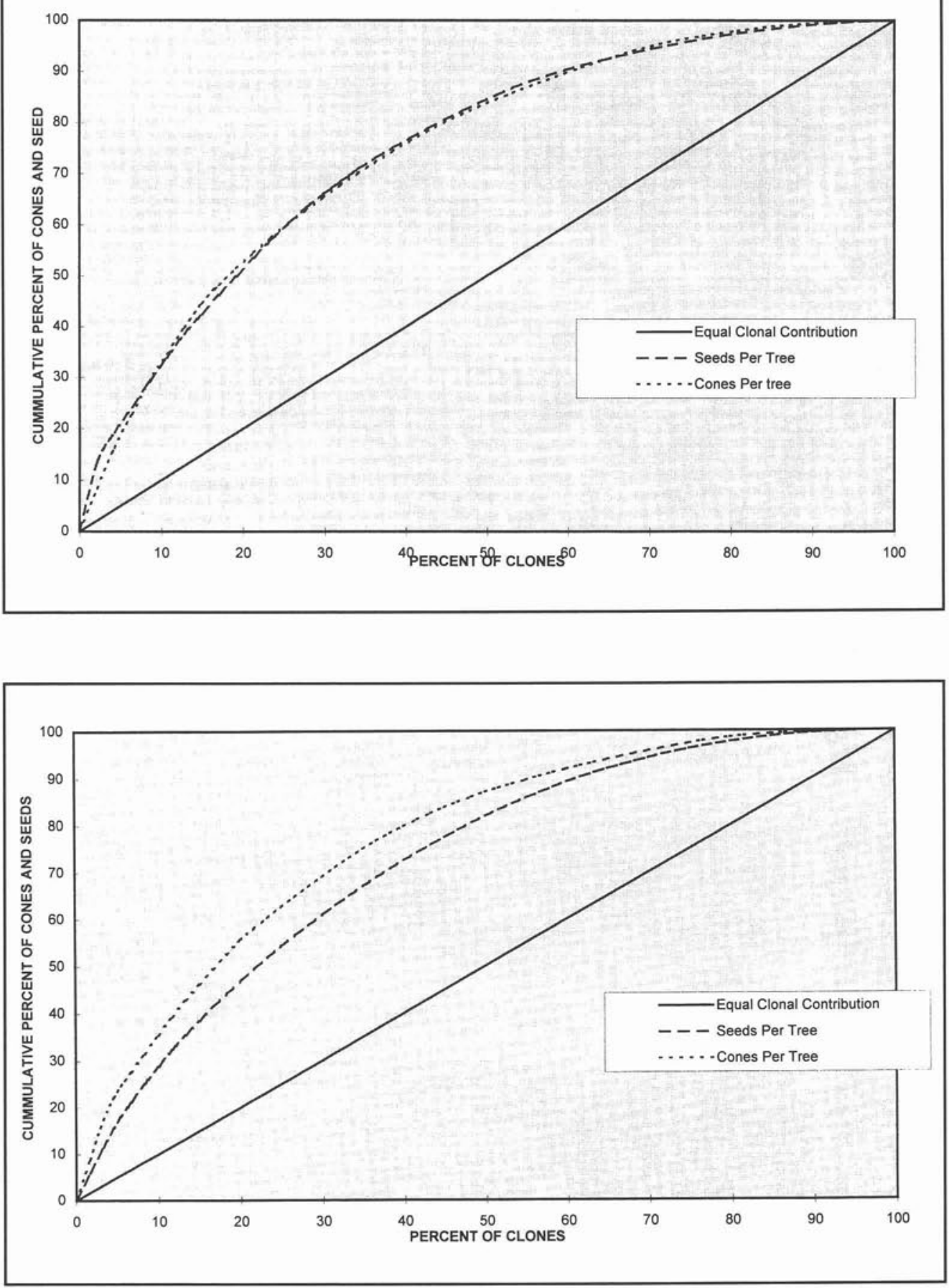

Fig. 3. Cumulative white spruce cone and seed production ranked by clonal contribution.
Fig. 4. Cumulative black spruce cone and seed production ranked by clonal contribution. seed curve falls inside the cumulative cone curve which means that the deviation from perfect balance is less for actual seed values than it is when cone tree ${ }^{-1}$ is used. Overall, the seed curves for black spruce and white spruce are similar although black spruce shows slightly better reproductive balance than white spruce. For example, 80 percent of the seed was produced by 49 percent of the clones in black spruce compared to 43 percent in white spruce.

\section{Discussion}

This study presents one-year findings on female reproductive balance at Parkindale Seed Orchard. Further observa- tions are needed to determine the overall balance of seed crops. The year-to-year variation in cone and seed production among clones should be evaluated to see if similar patterns occur through time. O'Reilly et al. (1982) suggested that the best reproductive balance is achieved in years with good cone crops; this was also illustrated by El-Kassaby (1992). This study took place in a very good cone year for both species. Fortunately, seed produced in good cone years form a large percentage of the total seed in storage for a species and these collections should receive priority in nursery deployment. Clearly, to provide information of use to the orchard manager, future studies must determine clonal contribution by sound seed produced because of 
the differences in ranking according to cone and seed production (Figs. 1 and 2). For some species, there are differences across clones in germination percentages (El-Kassaby 1992) which would be another factor to consider in orchard reproductive balance. This aspect was not examined because bulk seed orchard collections in 1994 yielded germination rates of $99 \%$ and $95.5 \%$ for black spruce and white spruce, respectively. There may be clones which have relatively low germination rates but these are likely to be very few; for example, results of germination tests conducted on 77 clones of jack pine from Parkindale Seed Orchard showed that 76 clones achieved $100 \%$ germination in the greenhouse, albeit at different germination rates (Adams and Kunze 1994). Variation in germination speed is not likely to be critical since single-seeding or at most, double-seeding, is practised in our operational nursery production. If multiple sowing with subsequent thinning is practised to ensure high container occupancy rates, seedlings from late germinating clones will be smaller at the time of thinning and these would have a greater probability of being culled from the seedling crop (ElKassaby 1992).

Pollen production and synchrony with female flowering has a large impact on reproductive balance in seed orchards (Xie et al. 1994). O'Reilly et al. (1982) noted that there was much greater variability in pollen production among trees than cone production. Pollen production was not evaluated in 1994. However, examination of past inventories recorded for tree breeding purposes indicates that considerable variation in pollen production among clones occurs in both the white spruce and black spruce orchards. This aspect should be investigated further. Differences in reproductive phenology are not likely to be a serious problem in our orchards. The reproductive phenology was examined for a range of clones through time and in general, the range in female cone receptivity is approximately eight days or less for both species (Adams 1992) with ranges being shorter in late springs. Pollen is shed throughout a similar period although a few clones of black spruce start to become receptive prior to pollen shed. The majority of clones show overlap in female receptivity and pollen shed with only a few clones being early or late (MacTavish 1988). Observations at Parkindale agree with those of O'Reilly et al. (1982) for black spruce which are that the differences in reproductive output are of much greater consequence than phenology when considering reproductive balance in a seed orchard.

Pollen contamination also influences genetic gain and genetic diversity. In this case, the orchards were located within the breeding zones for both species so any contamination was not likely to result in maladaptation of planting stock although it would still have an impact on realized gain from orchard seed. Low levels of pollen contamination could actually increase genetic diversity of orchard seed, but high levels could either increase or decrease diversity depending on the source of contamination. Background pollen was monitored during a five year period before significant pollen production began within the orchards (Adams 1992). Further monitoring is needed now that orchards are in full production. Previously detected levels were low for black spruce and white spruce compared to jack pine because of the scattered occurrence of the first two species in surrounding stands and sanitation measures conducted within the immediate vicinity of the orchard blocks.

Management options available to the orchard manager to promote better reproductive balance in seed orchards include selective harvesting, partial roguing, flower induction and supplemental mass pollination. The first three of these options are the cheapest and most practical in our present situation. Intervention will be aimed at the clones producing disproportionately high and low percentages of seed. In the short term, as more data are collected on year-to-year variation in balance across clones, the emphasis will be on harvesting cones from only a portion of the trees from clones producing high percentages of total seed. This approach is especially practical in light of the surplus seed supply situation. As further data on female and male reproductive balance and progeny performance are accumulated, partial roguing can be considered on clones with acceptable breeding values but disproportionately high reproductive contributions. Also, as progeny test information reveals which of the low seed producing clones have high breeding values, flower induction can be targeted to these clones. Application of GA4/7 has improved cone production dramatically in both black and white spruce (Greenwood et al. 1991) and the success of stem injection techniques has greatly reduced application costs, allowing this practice to be used on a wider scale (Greenwood et al. 1993). In general, much closer attention needs to be focused on reproductive balance as seed orchards are rogued to raise the overall average breeding value of clones represented. Information obtained in this study will be valuable for making orchard management decisions that will have impact on both the gain realized from seed orchards as well as genetic diversity of reforestation stock.

\section{Acknowledgments}

The review and suggestions by Drs. M.S. Greenwood, R.F. Smith, P. Hall and an anonymous reviewer are greatly appreciated.

\section{References}

Adams, G.W. 1992. Pollen monitoring studies in J.D. Irving Ltd. seed orchards and orchard management implications. Pp. 21-26 In: Proc. of Challenges in pollen dispersal and pollen contamination workshop, F. Di-Giovanni and D. Joyce, Eds. February, 1992, Egbert, ON. Environment Canada Report CCAD-92-008.

Adams, G.W. and H.A. Kunze. 1994. Variation in germination parameters across jack pine families originating from a J.D. Irving Limited seed orchard. Canadian Tree Improvement Association Tree Seed Working Group News Bulletin No. 20: 9-11.

El-Kassaby, Y.A. 1992. Domestication and genetic diversity should we be concerned? For. Chron. 68: 687-700.

El-Kassaby, Y.A. and C. Cook. 1994. Female reproductive energy and reproductive success in a Douglas-fir seed orchard and its impact on genetic diversity. Silvae Genetica 43(4): 243-246.

El-Kassaby, Y.A. and K. Ritland. 1992. Frequency-dependent male reproductive success in a polycross of Douglas-fir. Theor. Appl. Genet. 83: 752-758.

Greenwood, M.S., G.W. Adams and M. Gillespie. 1991. Stimulation of flowering by grafted black spruce and white spruce: a comparative study of the effects of gibberellin A4/7, cultural treatments, and environment. Can. J. For. Res. 21: 395-400.

Greenwood, M.S., G. W. Adams and S. Kempton. 1993. Using recent advances in the control of conifer reproductive development to increase genetic gain. Pp. 19-25 In: Proc. 24th Meeting of the Canadian Tree Improvement Association, J. Lavereau, Ed. 15-19 August 1993, Fredericton, NB.

MacTavish, B.A. 1988. Reproductive phenology of jack pine, black spruce and white spruce in a New Brunswick clonal seed orchard. University of New Brunswick, Unpublished B.Sc.F. thesis, 31 p. 
McPherson, J.A., E.K. Morgenstern and B.S.P. Wang. 1982. Seed production in grafted clonal orchards at Longlac, Ontario. For. Chron. 58: 31-34.

O'Reilly, C., H.W. Parker and J.E. Barker. 1982. Effect of pollination period and strobili number on random mating in a clonal seed orchard of Picea mariana. Silvae Genetica 31: 90-94.

Simpson, J.D. 1995. Thirteenth annual report of the New Brunswick Tree Improvement Council. Canadian Forest Service - Maritimes. $27 \mathrm{pp}$.
Xie, C.Y., J. Woods and M. Stoehr. 1994. Effect of seed orchard inputs on estimating effective population size of seedlots - a computer simulation. Silvae Genetica 43(2-3): 145-154.

Zobel, B.J. and J.T. Talbert. 1984. Applied tree improvement. John Wiley and Sons, New York, NY. 505 p. 